\title{
Maintenance Management in a Health Care Establishment
}

\author{
Fabricio Avelino Bispo*; Marinilda Lima Souza; Sérgio Pitombo \\ Centro Universitário SENAI CIMATEC; Salvador, Bahia, Brazil
}

\begin{abstract}
With the accelerated growth of the health area in Brazil, institutions increasingly seek to optimize the operations by leveraging the results and becoming competitive in the market. Ensuring the high availability of infrastructure and assets provides that the organization is a strategic tool to achieve positive productivity results. However, it is necessary to structure the engineering department of the maintenance and correct administration of the flows that integrate the sector to meet the expected results. The use of computerized maintenance control tools helps in the management of environments and equipment, assuring the operational reliability of the health care establishment. This article presents the stages of implementation of management and maintenance in a health care establishment. The results demonstrate the evolution in the control of the maintenance department with greater efficiency, planning, increased availability of infrastructure and equipment as well as reduced costs for the operation of health sector processes in Brazil.
\end{abstract}

Keywords: Maintenance Management. Assets. Maintenance Software. Availability. Reliability.

Healthcareorganizationsareseekingalternatives to reduce costs in their operations and optimize production to ensure sustainability with the use of new technologies and the high competitiveness in the market. Some factors affect and interfere in the patient expectations to care to receive according to Establishing Health Outreach (EHO) [1]. For such reasons, EHO needs to be organized to ensure full recovery of the patient's condition. It is essential to provide the operability of the infrastructure and medical equipment to maintain the quality of the provision of services in a healthcare establishment. Intervention management of assets should be carried out correctly and in an organized manner. The maintenance department is essential for ensuring the availability and reliability of equipment and installations. It provides the quality of the final product, making it a strategic sector in a health care setting. This article presents the implementation of a maintenance management program in a healthcare establishment through the application of maintenance management software.

Received on 21 February 2019; revised 8 March 2019.

Address for correspondence: Dr. Fabricio Avelino Bispo. Centro Universitário SENAI CIMATEC. Avenida Orlando Gomes, 1845 - Piatã; Salvador, Bahia, Brazil. E-mail: fabricioavelino1@yahoo.com.br.

J Bioeng. Biotech. Appl. Health 2019;2(1):27-33

(C) 2019 by SENAI CIMATEC. All rights reserved.

\section{Maintenance Management of Hospital Equipment}

Slack and colleagues (2004) [2] classify the following objectives of maintenance: higher product quality, cost reduction, greater safety, better work environment, longer equipment life and, the most important of all, higher reliability of equipment. An effective maintenance management system is one that consists of the elaboration and fulfillment of a maintenance plan. This plan will enable the company to achieve profitability and survival goals with equipment, which not fail nor impair the quality, cost, and delivery of products and services and does not jeopardize the safety and integrity of the environment [3]. The current demands of the area of maintenance of healthy environments should have strategies to improve the safe use of equipment, reduce operating costs and seek guidance in documents from the Ministry of Health [4]. The healthcare environment should be kept in constant operation, adopting best practices and running healthy and environmentally responsible places.

We analyzed the implementation of a maintenance management system, the Smart Clin, software available in health care establishments. The steps of deploying the software involved planning, data collection, and data analysis, implementation of a preventive maintenance plan, training, operation and interpretation of 
results guided by the PDCA cycle. These steps are a management tool that the goal is to promote continuous improvement of processes using four actions: Plan, Carry out the plan, Check and Act.

\section{Case Report}

The present case study was carried out in a leading company for the provision of imaging diagnosis healthcare services, located in the state of Bahia. Maintenance management software was implemented to map, organize and manage the processes of the department. The planning for project development initiated in the second half of 2016 and the analyzed data correspond to 2017. The financial results of the department were compared to evaluate the effectiveness of the project. It is noteworthy that the establishment did not have a defined and organized maintenance department, so the demands were solved as they were identified in the EHO operation routine. There was no control over procedures, cost management and/or application of labor in the maintenance area.

\section{Smartclin Software}

TheSmartClinSoftware is a tool for managing services in health units. It consists of several application modules such as supplies, invoicing, human resources and care. Among the modules available, the module "Manut" is for maintenance management and had been inactive in the EHO due to the lack of administration of the department. It is noteworthy that the results of the project were analyzed in the monthly costs of maintenance of building infrastructure and support equipment.

PDCA cycle was used for the implementation of management and software. Figure 1 illustrates the PDCA cycle.

During the planning stage, the following maintenance system objectives were defined:

- Control of preventive maintenance of the building;

- Control of preventive maintenance of support equipment (refrigeration, air-conditioning, generators, etc.);
Figure 1. PDCA cycle.

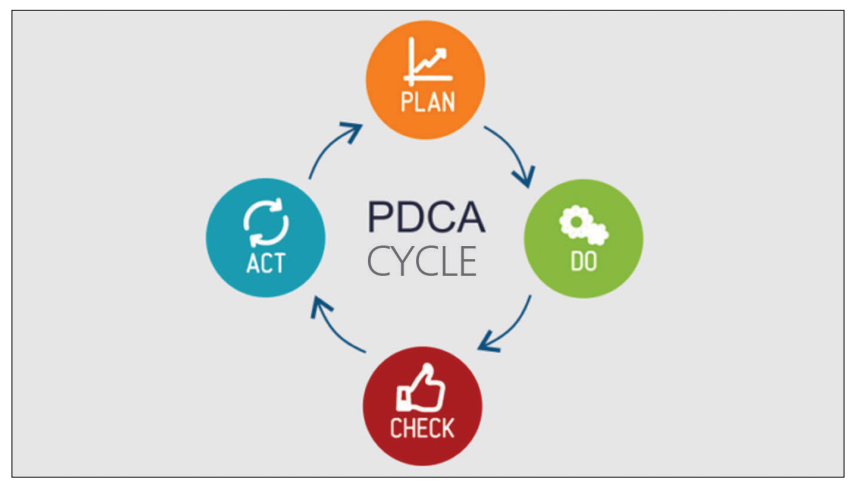

Source: Filho, G.B. (2005)

- Control of corrective maintenance in equipment and infrastructure;

- Define the sector flowchart.

We developed action plans to achieve these objectives through the $5 \mathrm{~W} 2 \mathrm{H}$ tool. A management tool allowed to organize actions and distribute activities to have a specific result, usually used in a spreadsheet or table format. It consists of 7 questions in English of which 5 start with $\mathrm{W}$ and 2 start with $\mathrm{H}$, as follows:

- Why? - Why is it done?

- What? - What will be done?

- Where? - Where will it be done?

- When? -When will it be done?

- Who? - Who will it be done?

- How? - How will it be done?

- How Much? - How much it will be cost?

\section{Managing EHO Maintenance}

Macros' tasks were registered for system implementation in the plan of action, as well as the process model and the main activities called flowcharts. The goal of the diagrams (Figures 2 and 3) was to show the team and the department how the maintenance department can meet its internal and external clients with all the steps required to complete a specific task. The flowchart in Figure 2 illustrates the steps of planning, execution, and control of preventive maintenance. 
Figure 2. Preventive maintenance flowchart.

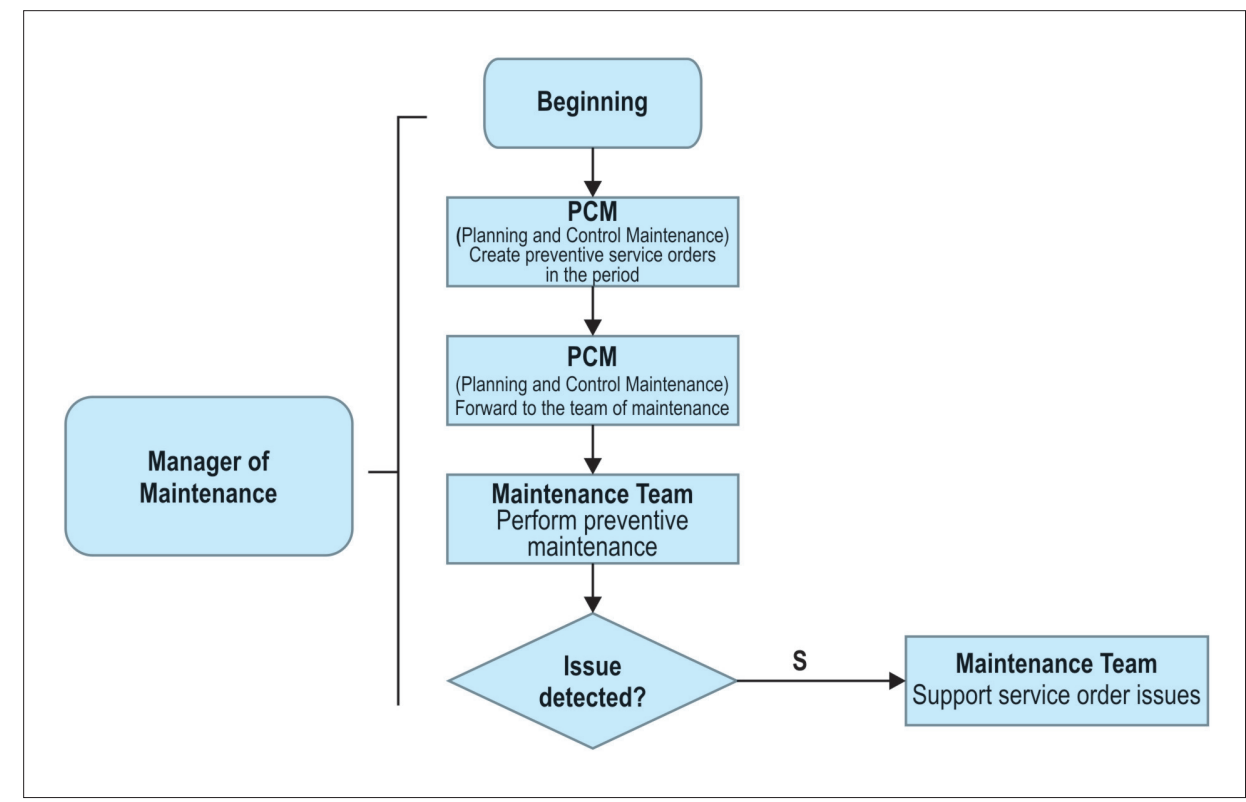

Figure 3. Flowchart corrective maintenance.

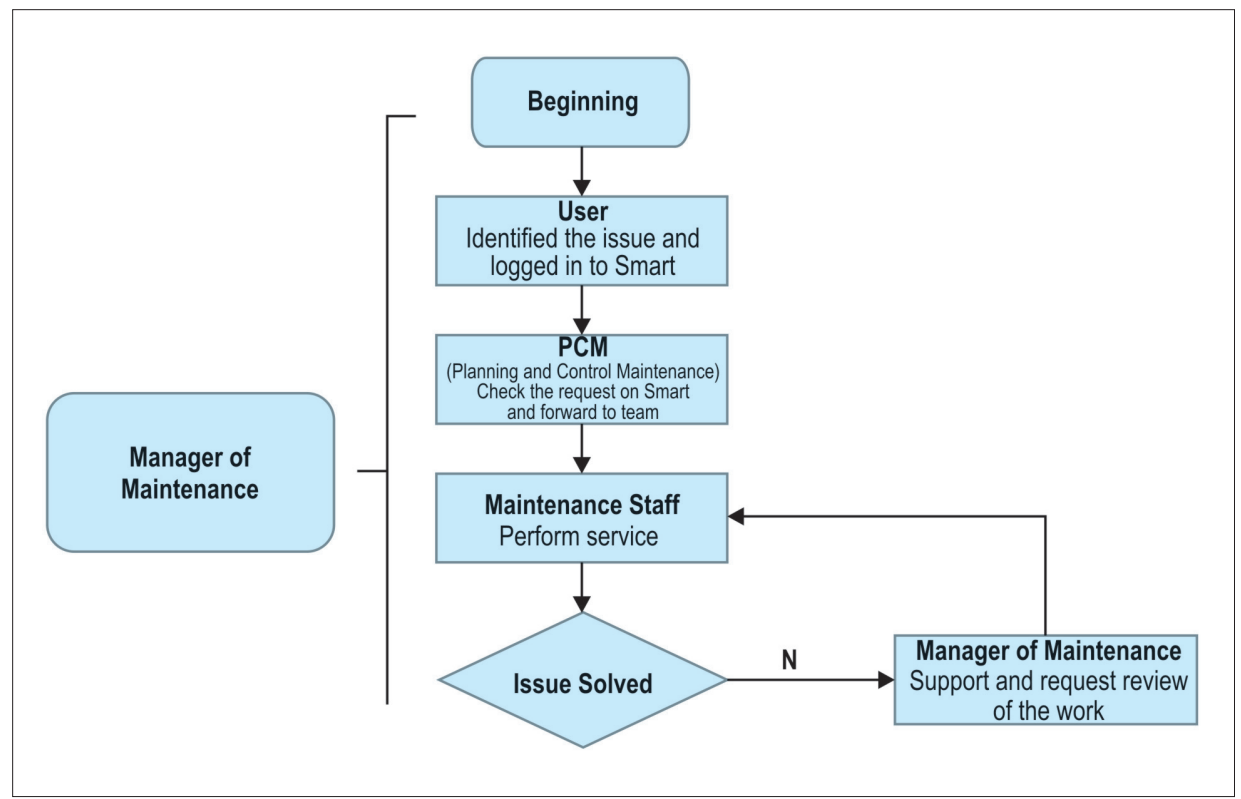

The flowchart in Figure 3 illustrates the steps for the opening, conducting and control of corrective maintenance.

\section{System Deployment}

After the planning steps, the step of collecting data and parameter settings for structuring the operational database system was initiated. Figure
4 shows the initial screen for the data to access the system.

The infrastructure equipment to be inserted in the system was initially defined, and equipment groups were created to facilitate the identification of assets and their management of the operation. After entering the equipment, setting the criticality of material was also carried out to classify the 
Figure 4. Smart system access screen.

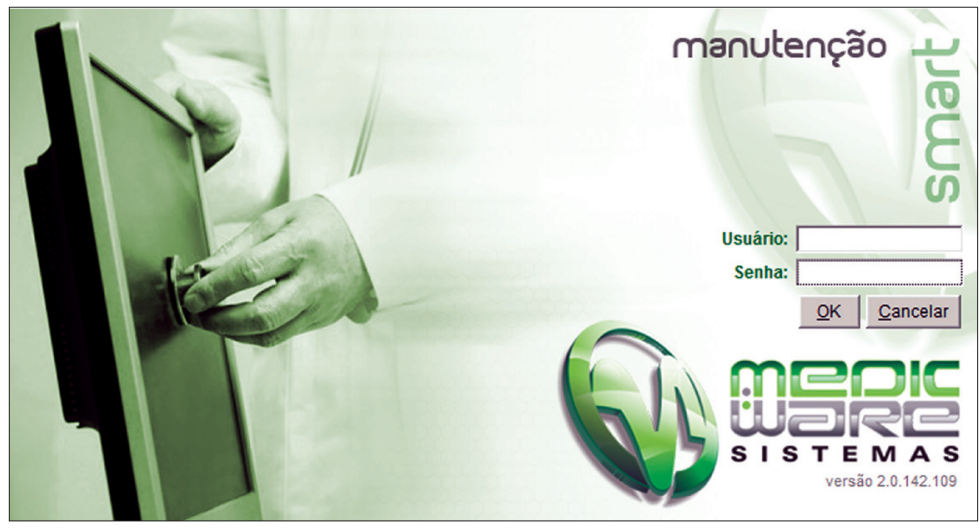

Source:MedicWare (2018).

requests and orders of service according to the degree of importance of the asset before the drive.

The criticality of assets as defined in 4 categories, below:

a) Low-active, which does not interfere with the operation of the unit nor the safety of users.

b) Medium-active, which can interfere with the operation of the unit, but does not interfere with the protection of users.

c) High-active, which interferes directly in the process of the unit, affecting the productive chair, but does not present risks to users.

d) Urgent-active, which interferes directly in the production of the unit, and puts users at risk.

After the definition of the groups, the of the imported equipment by equipment for entries in the software such as air conditioning, generators, chillers, no-breaks, etc. Due to the particularities of the system, it was necessary to carry out the registration of physical environments as well as equipment, only in this way was it possible to perform the opening of corrective services requests. For the register of the equipment, the information of the essential features of the asset was considered, such as make, model and serial number. It was used to optimize the time of registration in the field of equipment ensuring deadlines. Figure 5illustrates the equipment registration screen.

For the opening of requests for corrective services, it was necessary to register the types of remedial maintenance services, both for equipment and for infrastructure in general. The definition of corrective service requests allows the measurement of data to help in the decision making based on the data collected. Also in this step, the average times foreseen for the resolution of each service request are indicated. The service request resolution period is also made available to the user during the opening of a service request, allowing them to know instantly when their application will be answered.

During the implementation of the software, the preventive maintenance procedures were also defined, to assist the maintenance team in accomplishing and fulfilling the maintenance plans. The entire maintenance team was involved in meetings and brainstorming tapping the experiences of each team member to collect this data. The procedures were recorded in a spreadsheet and then imported into the system.

\section{System Operation}

After the implementation phase, data collection, training and testing the policy went into full operation and became the primary tool for management and maintenance of the EAS. The services department of both corrective maintenance and preventive maintenance began to be managed through the software.

Through a maintenance request, it is possible to perform the control of work orders in the system, such as date, time, equipment, activities to be 
Figure 5. Equipment register.

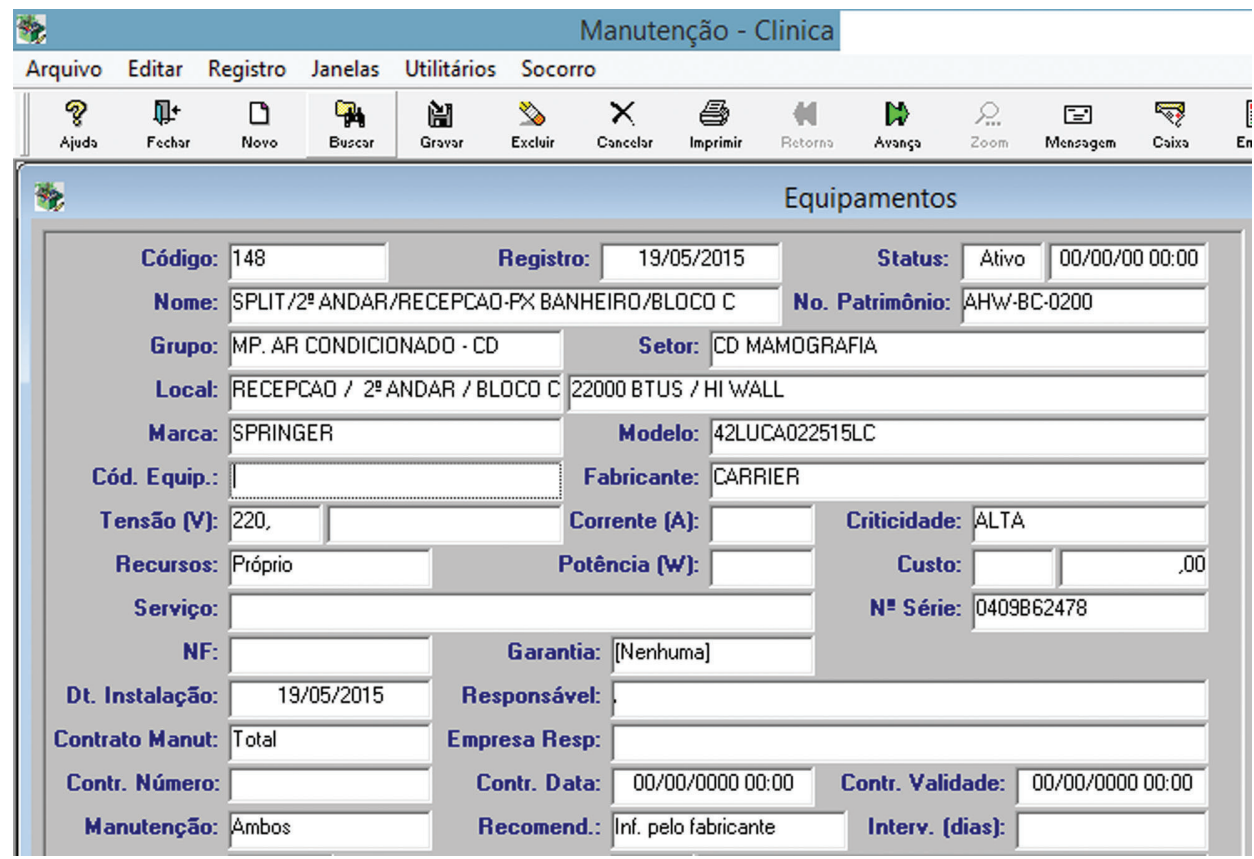

Source:MedicWare (2018).

carried out, the status of orders and services, etc. With the use of the existing filters service orders, groups of equipment, service status, deadlines and a range of information can also be found.

The maintenance teams are requested to perform an activity through a printed document called the service order. With this, the maintenance team can identify the information needed to achieve the operation, such as the applicant, the action that needs to be performed, the location of the equipment and the service sector.

After servicing by a specialized technician, the service is terminated in the system with the upload of the physical document signed by the applicant and the release of all the data recorded by the performer of the service.

\section{Results and Discussion}

With the organization, implementation, and operation of this piece of maintenance software, the process of evaluating and managing the data in the system was initiated. With reliable information about easy access, it was possible to carry out the analysis of the data contributing significantly to decision making and the strategic management of maintenance activities.

Among these actions are the acquisition of new equipment, replacement of equipment, needs for works and repairs, logistics of team attendance among others.

The possibility of measuring data with the elaboration of maintenance indicators is essential to accompany the overall performance of the department. Data are stratified at various levels such as units, locations, sectors, and services, facilitating analysis and problem-solving. After a 12-month cycle of maintenance software operation, the primary data of the department were evaluated to analyze the effectiveness of the implementation of the project. The data for the service orders can be seen in Graphic 1.

The amount of preventive maintenance increased, and corrective maintenance fell by almost 50\%. A survey was also carried out regarding the costs related to the maintenance department. Graphic 2 illustrates these results.

A significant reduction in department costs can be observed, $46.7 \%$ at the end of the year. These data demonstrate the effectiveness of the 
Graphic 1. Preventive service orders x corrective.

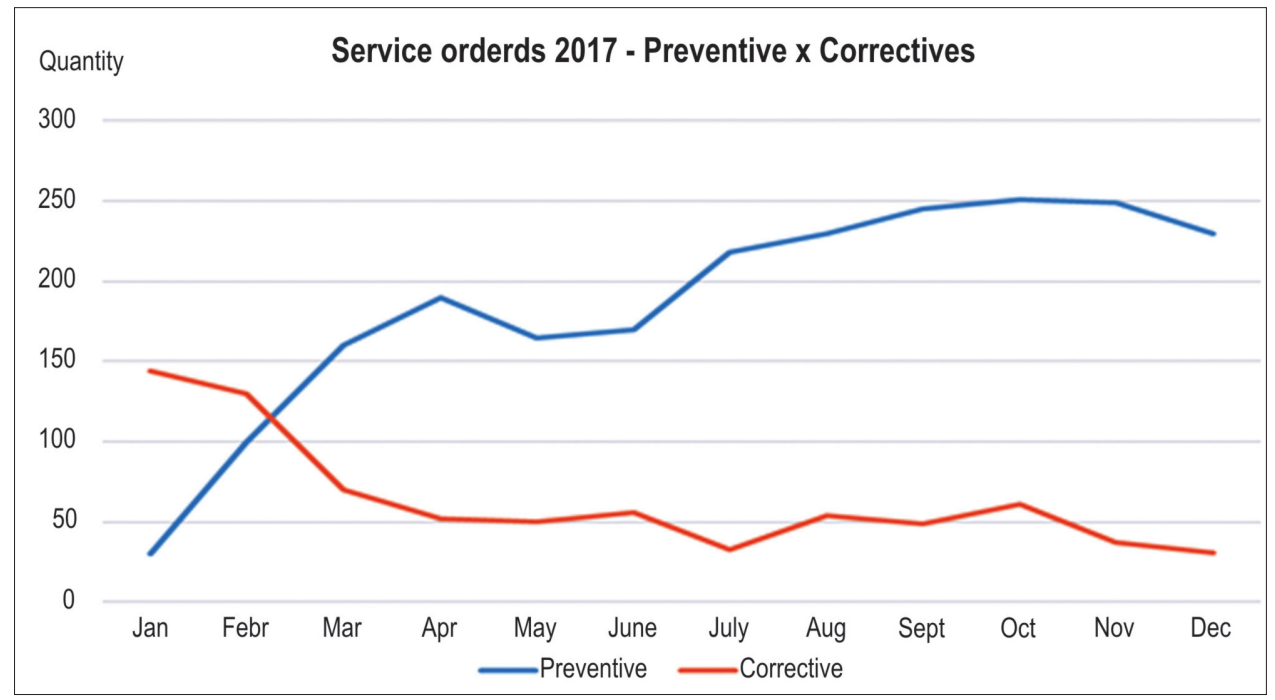

Graphic 2. Cost chart for infrastructure maintenance.

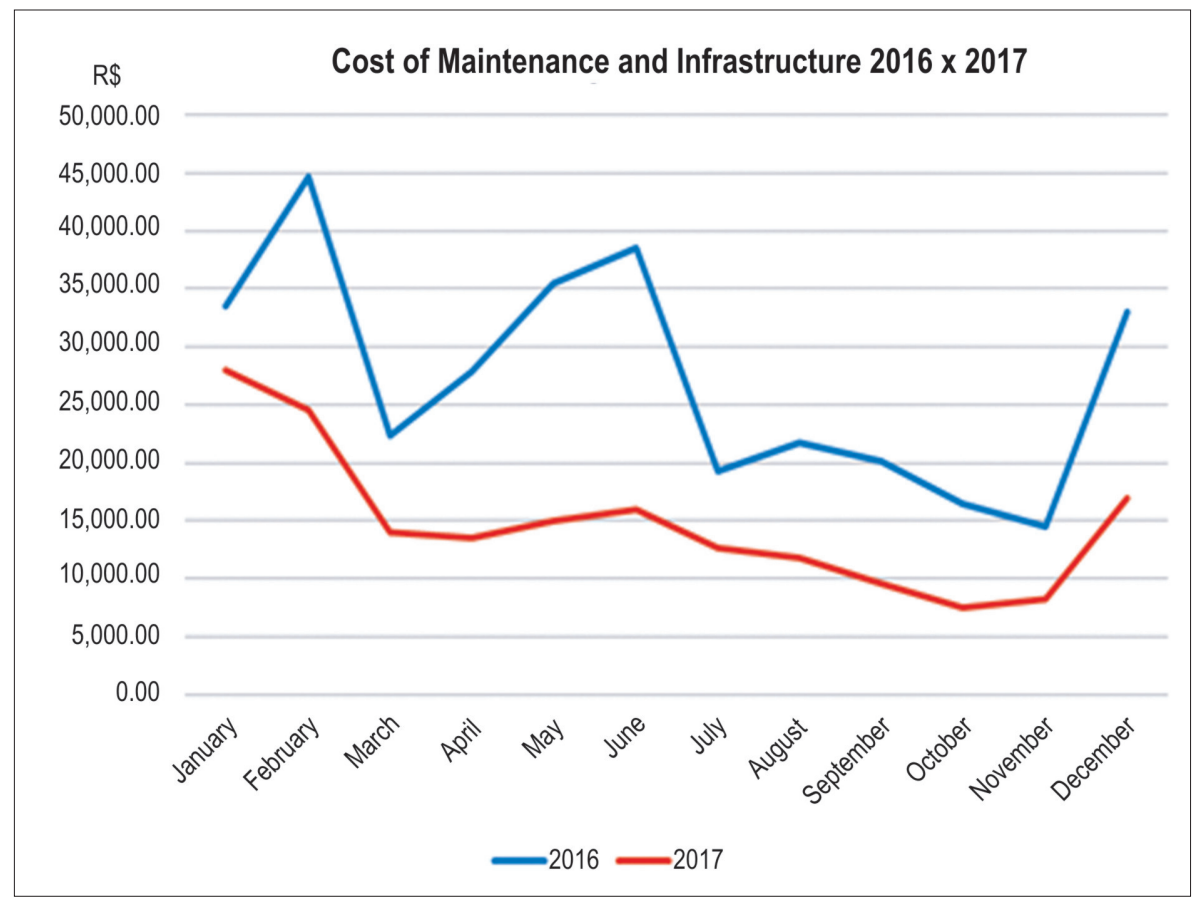

implementation of a maintenance management system and the applicability of maintenance tools in the health care establishment.

\section{Final Considerations}

With the result of the project and the consolidation of the use of the software, it was possible to promote the management of maintenance in the health care establishment. The planning, standardization, and control of the operational routines of the department were consolidated. In this project there was a more significant concern in structuring the maintenance sector initially, adopting simple and satisfactory practices and methods. With the implementation of preventive and corrective maintenance routines, there was an increase in the availability of facilities and equipment, contributing directly and actively to the quality of services provided by the establishment. 
After the presentation of the results to the organization's senior management, the maintenance department became a strategic function in the company, joining this new stage to the Department of Clinical Engineering.

The challenge and the next steps will be to improve the use of the software by implementing new strategies and consolidating practices seeking continuous improvement of processes, and the technical capacity of the team involved to ensure the best results for the Maintenance Management and consequently, for the organization and its users.

\section{References}

1. Gonçalves, E.L. Gestão Hospitalar: administrando o hospital moderno.1. Ed. São Paulo:Saraiva, 2007.

2. Slack, N., Chambers, S., Johnston, R. Administração da Produção. São Paulo: Atlas, 2002.

3. Xenos, H.G. Gerenciando a Manutenção Produtiva. Belo Horizonte: INDG, 2004.

4. Guimarães, J.M.C., Gondim, G.M. O papel da politécnica na formação profissional de técnicos de nível médio envolvidos na área de manutenção predial e de equipamentos em estabelecimentos assistenciais de saúde (EAS), Rio de Janeiro, 2008.

5. Filho, G.B. Auditoria em Manutenção: VIII Congresso de manutenção Semapi. 5. 2003. São Paulo: SEMAPI, 2003.

6. Medic Ware (2018) 